\title{
ANALISIS VIDEO LIKES TO FOLLOWERS RATIO TIKTOK PADA 5 E-COMMERCE YANG BANYAK DIKUNJUNGI DI INDONESIA
}

\author{
I Gusti Agung Made Krysna Putra \\ krisptra97@gmail.com
}

\begin{abstract}
TikTok is an application originating from China, this application provides a variety of unique and interesting special effects, this feature can be used by all TikTok users very easily while making short videos, and this application is used practically to edit sharing short videos with a duration of 15 seconds to all other users. In Indonesia TikTok is a popular social media, and Indonesia is one of the countries with the largest TikTok users. This phenomenon is utilized by the company to be used as an opportunity to spread the products offered by creating a TikTok account. There are 5 most visited e-commerce in Indonesia that use TikTok social media as a marketing tool, including: Tokopedia, Shopee Indonesia, Bukalapak, Lazada Indonesia, and Blibli. In this study, it intends to measure the credibility performance of 5 TikTok e-commerce accounts that are most visited in Indonesia. The method used in this study is quantitative exploratory. This study proved that Tokopedia e-commerce accounts ranked first and had the best account performance among the five accounts studied.
\end{abstract}

\begin{abstract}
ABSTRAK
TikTok merupakan aplikasi yang berasal dari Tiongkok, aplikasi ini menyediakan bermacam special effect yang unik dan menarik, fitur tersebut bisa digunakan oleh semua pengguna TikTok dengan sangat mudah ketika membuat video pendek, dan aplikasi ini dipergunakan secara praktis untuk mengedit membagikan video pendek dengan durasi 15 detik kepada seluruh pengguna lainnya. Di Indonesia TikTok merupakan media sosial populer, dan Indonesia menjadi salah satu negara dengan pengguna TikTok terbesar. Fenomena ini dimanfaatkan oleh pihak-pihak perusahaan untuk dijadikan peluang menyebarkan produk yang ditawarkan dengan cara membuat akun TikTok. Terdapat 5 e-commerce yang banyak dikunjungi di Indonesia yang memanfaatkan media sosial TikTok sebagai alat marketing, diantaranya: Tokopedia, Shopee Indonesia, Bukalapak, Lazada Indonesia, dan Blibli. Dalam penelitian ini bertujuan untuk mengukur kredibilitas performa akun 5 TikTok e-commerce yang banyak dikunjungi di Indonesia. Metode yang dipergunakan pada penelitian ini adalah eksploratif kuantitatif. Dari penelitian ini menunjukan bahwa akun e-commerce Tokopedia meraih peringkat pertama serta mempunyai performa akun yang paling baik diantara kelima akun yang diteliti.
\end{abstract}

Keyword: TikTok Social Media; Credibility TikTok Account; Social Media Marketing; Video Likes to Followers Ratio; Indonesia E-commerce Company. 


\section{PENDAHULUAN}

Dalam kehidupan, teknologi atau ilmu cara tidak dapat dipisahkan. Teknologi ini sangat membantu dalam menuntun manusia ke era modern. Salah satu teknologi yang membantu adalah teknologi informasi, dengan ini pengguna dapat membuat, manipulasi, mengarsipkan, dan mengkomunikasikan sesuatu dengan pengguna lainnya. Salah satu teknologi informasi adalah sosial media yang diaplikasikan melalui berbagai platform. Sosial media umumnya membantu pengguna untuk saling berkomunikasi serta menjadi media mengekspresikan diri. Sosial media juga mendukung penggunanya dalam berselancar di dunia maya, dan memberi rungan untuk kegiatan bisnis.

Modernisasi teknologi memberi dampak yang signifikan kepada sosial media. Sosial media yang terdahulu dapat terbilang kalah dibandingkan suksesornya baik, dari segi fitur ataupun tampilan dari aplikasi sosial media tersebut. Pada saat ini media sosial dipandang populer oleh masyarakat dikarenakan digitalisasi yang menyebar sangat pesat. Contoh dari sosial media yang populer saat ini yaitu TikTok. TikTok merupakan aplikasi berasal dari Tiongkok yang diluncurkan pada awal September tahun 2016, aplikasi ini dipergunakan untuk membagikan video pendek dengan durasi 15 detik kepada seluruh pengguna lainnya (Winarso 2021).

Media sosial memiliki dampak yang cukup besar terhadap masyarakat Indonesia, terutama media sosial TikTok membuat para pelaku usaha memiliki pilihan untuk bisa menawarkan jasa dan produknya ke berbagai daerah lebih mudah (Wibowo dan Yudi 2021). Di Indonesia TikTok merupakan media sosial yang sangat populer, dan Indonesia menjadi salah satu negara dengan pengguna TikTok terbesar. Fenomena ini dimanfaatkan oleh pihak-pihak perusahaan untuk dijadikan peluang menyebarkan produk yang ditawarkan, dengan cara membuat akun TikTok. Telah banyak perusahaan yang memanfaatkan TikTok tidak terkecuali perusahaan $e$-commerce.

Pada penelitian ini, metode yang digunakan yaitu eksploratif kuantitatif, serta penghitungan menggunakan rasio-rasio yang tersedia pada TikTok. Terdapat 17 rasio yang relevan dipergunakan untuk media ukur kredibilitas akun untuk kasus penelitian analisis media sosial TikTok (Permana dan Meinarni 2021). Pada kasus yang diambil penulis hanya berfokuskan pada satu rasio yaitu Video Likes to Followers Ratio pada 5 ecommerce yang banyak dikunjungi di Indonesia. Adapun 5 e-commerce yang banyak dikunjungi di Indonesia, yaitu: Tokopedia, Shopee, Bukalapak, Lazada, dan Blibli (Catriana 2021). Adapun tujuan dari kegiatan penulisan penelitian ini yakni mencari tahu kredibilitas performa dari akun TikTok 5 e-commerce yang banyak dikunjungi di Indonesia menggunakan Video Likes to Followers Ratio. 


\section{TINJAUAN PUSTAKA}

Teknologi mengalami perkembangan dari masa ke masa. Dengan perkembangan ini muncul adanya ide-ide yang diimplementasikan, salah satunya adalah aplikasi sosial media. Aplikasi sosial media ini dapat dikatakan sangat populer, karena pengguna dari sosial media ini relatif banyak. Adapun jenis dari aplikasi sosial media yang marak dipergunakan oleh masyarakat diantaranya Instagram, Twitter, Facebook, WhatsApp, Telegram, TikTok dan lain-lain. Kepopuleran dari sosial media pada kalangan masyarakat dikarenakan sosial media membantu pengguna berkomunikasi dengan orang lain, informatif, memiliki unsur entertainment dan faktor-faktor lainnya.

TikTok adalah aplikasi praktis yang bisa dipergunakan dimana saja dan kapan saja, dalam pembuatan materi konten terbilang bebas sehingga content creator dapat berbagi banyak hal, tanpa terfokus pada satu topik atau tema yang ingin dibagikan di media sosial, dan tidak membutuhkan banyak properti atau tempat khusus dalam pembuatan kontennya (Wibowo dan Yudi 2021). TikTok termasuk aplikasi yang tergolong aktif dipergunakan oleh pengguna dari penjuru dunia. TikTok merupakan aplikasi yang menyediakan berbagai macam special effect yang unik dan menarik, fitur tersebut bisa digunakan oleh semua pengguna TikTok dengan sangat mudah ketika membuat video pendek (Batoebara 2020). Aplikasi TikTok memberikan sesuatu hal yang unik dan menarik sehingga pengguna dapat dengan mudah membuat video pendek yang didukung dengan musik yang banyak, sehingga menghasilkan performa yang bagus dan menarik (Suryani, Zulfikri, dan Muhariani 2021).

Terdapat fenomena di Indonesia, dimana anak muda menggunakan media sosial TikTok untuk menunjukkan antusiasme serta berlomba membangun identitas diri demi mendapatkan citra yang mereka inginkan (Handy Dwi Wijaya 2020). Dengan adanya fenomena tersebut, TikTok mengalami peningkatan kepopuleran khususnya di Indonesia. Sejak awal 2021, aplikasi TikTok telah diunduh oleh sekitar 30 jutaan users di Indonesia, Masuk sebagai kategori Highest Grossing App versi Apptopia, TikTok mengalahkan Tinder, YouTube, Disney Plus dan lain-lain serta berhasil menjadi salah satu aplikasi paling populer dan menghibur sepanjang tahun 2020 dengan total pengguna kurang lebih 850 jutaan di seluruh dunia (Setyowati 2021).

Aplikasi TikTok bukan hanya sebatas media sosial untuk kegiatan hiburan, adapun kesempatan yang bisa dimanfaatkan oleh perusahaan. Kesempatan dari TikTok ini yakni, memiliki keuntungan dalam kegiatan promosi seperti memberikan informasi yang memadai tanpa biaya tinggi, tenaga banyak, dan dapat dilakukan dalam waktu yang relatif singkat (Dewa dan Safitri 2021). Dengan ini, TikTok bisa memberikan ruang untuk para pengusaha dalam kegiatan digital marketing.

TikTok dapat mempengaruhi perusahaan-perusahaan yang memanfaatkan dari peluang yang diberikan dengan cara membuat dan mengelola akun TikTok. Kualitas akun menentukan strata dan kredibilitas akun. Kredibilitas akun TikTok ini bisa memberikan pemilik akun momentum, seperti digital marketing yang efektif. Kredibilitas sebuah akun ini diukur dari tingkat performa yang dihasilkan secara matematis, dan pengukuran ini dituangkan kedalam skala rasio (Permana dan Meinarni 2021). 


\section{METODE PENELITIAN}

Dalam penelitian ini penulis mempergunakan metode eksploratif kuantitatif dalam pencarian kredibilitas performa 5 akun TikTok e-commerce yang banyak dikunjungi di Indonesia. Penelitian Eksploratif adalah studi dengan cara melakukan penelusuran, terutama dalam pematangan konsep yang akan dipergunakan dalam ruang lingkup yang penelitian yang lebih luas dengan jangkauan konseptual yang lebih besar (Yusuf 2017).

Adapun tujuan dari penelitian ini diantaranya untuk mencari nilai kredibilitas dan performa 5 akun TikTok e-commerce yang banyak dikunjungi di Indonesia. Adapun langkah-langkah yang ditempuh dalam pelaksanaan penelitian ini guna bisa menemukan peringkat pertama dari 5 akun TikTok tersebut. Berikut langkah-langkah penelitian yang dilaksanakan, diantaranya:

\section{Melakukan Eksplorasi Pada Website Untuk Menentukan Objek yang Akan Dianalisis.}

Eksplorasi diawali dengan mencari halaman website relevan yang menyajikan informasi tentang objek yang dianalisis. Pada kasus ini ditemukan halaman website yang berisikan sejumlah e-commerce yang banyak dikunjungi di Indonesia, penulis menjadikan kasus ini sebagai objek analisis. Setelah eksplorasi dilakukan, selanjutnya penulis mencari akun TikTok sesuai dengan nama $e$ commerce, dan memastikan bahwa e-commerce tersebut memiliki akun official TikTok.

\section{Menghitung Nilai Rata-Rata Variabel Dari 5 E-Commerce yang Banyak Dikunjungi di Indonesia.}

Pada langkah ini, penulis menghitung nilai rata-rata variabel Video Likes, hal tersebut dikarenakan variabel ini memiliki data yang jamak pada setiap akun. Variabel adalah sesuatu yang bernilai bervariasi, nilai tersebut bisa dijadikan sebagai fondasi empat data yang berbeda seperti rasio, skala, ordinal, nominal dan internal (Rankuti 2015). Dalam penghitungan nilai rata-rata pada variabel Video Likes, dilakukan dengan cara mengutip minimal 10 unggahan, lalu dihitung hingga diperoleh nilai rata-rata dari masing-masing variabel.

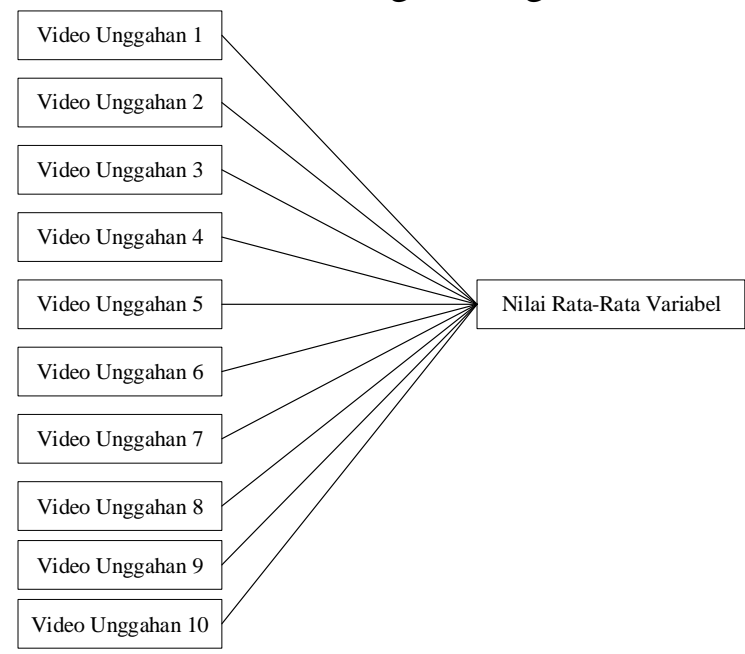

Gambar 1. Analisa Nilai Rata-Rata Variabel. 


\section{Menghitung Nilai Kredibilitas Rasio}

Dalam menghitung nilai kredibilitas dari Video Likes to Followers Ratio, penulis membagi nilai variabel pertama dengan nilai variabel kedua. Misalkan Video Likes memiliki nilai 10 dan Follower memiliki nilai 50, cara hitung sebagai berikut $10: 50=0,2$. Jadi nilai dari Video Likes to Followers Ratio adalah 0,2.

\section{Menentukan Peringkat Pada Akun TikTok}

Menentukan peringkat merupakan langkah lanjutan yang harus penulis lakukan untuk menyelesaikan penelitian. Peringkat diperoleh dengan cara memperhatikan karakteristik rasio yang dianalisis. Bila karakteristik rasio rendah, maka akun dengan nilai terendah akan diberikan angka 5 dan akun yang dengan nilai tertinggi akan diberikan angka 1. Namun bila rasio memiliki karakteristik tinggi, maka akun dengan nilai tinggi akan diberikan angka 5 dan akun dengan nilai terendah akan diberikan angka 1. Setelah memperoleh hasil kredibilitas rasio, maka penarikan kesimpulan dari akun yang mana akan diberi peringkat 1 sampai peringkat 5 dapat dilakukan.

\section{HASIL DAN PEMBAHASAN}

Berikut lima akun TikTok E-commerce yang banyak dikunjungi di Indonesia, yaitu:

\section{Tokopedia}

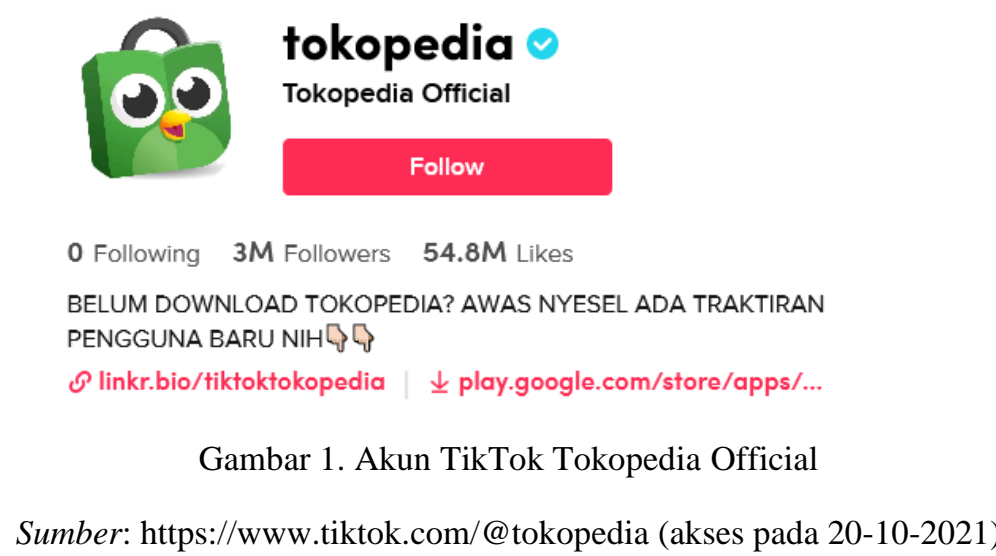

\section{Shopee Indonesia}

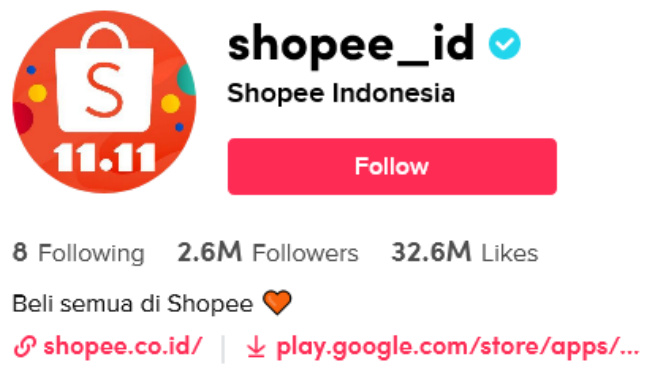

Gambar 2. Akun TikTok Shopee Indonesia 


\section{Bukalapak}

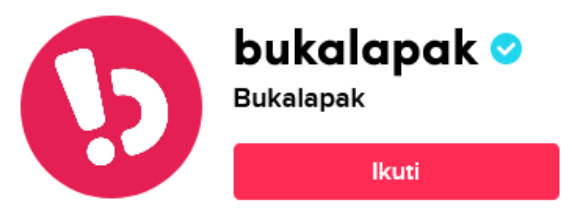

4 Mengikuti $379 \mathrm{~K}$ Pengikut $6.1 \mathrm{M}$ Suka

NO ONGKIR sepuasnya \&amp; semua bisa dapat voucher s.d Rp1 Juta di \#HarBOBOLnas1010

$\odot$ bl.id/kumpulink_OfficialBuka... | \pm play.google.com/store/apps/..

Gambar 3. Akun TikTok Bukalapak

Sumber: https://www.tiktok.com/@bukalapak (akses pada 20-10-2021)

\section{Lazada Indonesia}

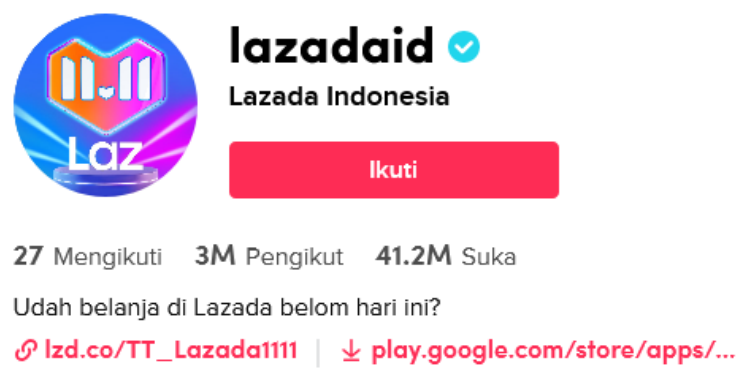

Gambar 4. Akun TikTok Lazada Indonesia

Sumber: https://www.tiktok.com/@lazadaid (akses pada 20-10-2021)

\section{Blibli}

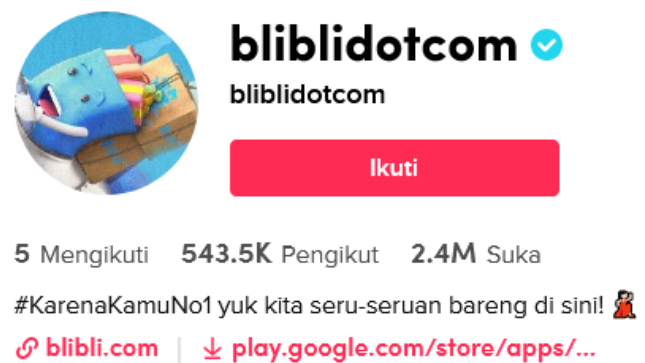

Gambar 5. Akun Bliblidotcom

Sumber: https://www.tiktok.com/@bliblidotcom (akses pada 20-10-2021)

Pada kelima akun TikTok E-commerce yang banyak dikunjungi di Indonesia, penulis mencari nilai variabel yang ada untuk menghitung Video Likes to Followers Ratio dari lima akun tersebut. Akun TikTok terdapat 7 variabel yang bisa dipergunakan, diantaranya yaitu:

- Likes

- Followers

- Following

- Video Likes

- Video Comments 
- Video Share

- Video Views

Dari ketujuh variabel di atas penulis hanya hanya perlu menemukan hasil dari 2 variabel, yaitu:

- Video Likes

- Followers

Dua variabel diatas kemudian dianalisis sampai nilai dari variabel Video Likes dan variabel Followers. Pada variabel Video Likes terdapat banyak video yang ada di sebuah akun TikTok, maka untuk mendapatkan nilai yang relevan perlu mencari minimal 10 video dan menghitung rata-rata Video Likes pada setiap akun. Pada variabel Follower setiap akun memiliki yang nilai sesuai di halaman akun, maka nilai variabel tersebut bisa dipergunakan ke tahap selanjutnya tanpa menghitung nilai rata-rata. Berikut tabel nilai rata-rata Video Likes dan nilai Followers:

Tabel 1. Analisis Nilai Rata-Rata pada Variabel Video Likes dan Analisa Nilai Variabel Followers Akun TikTok Tokopedia.

\begin{tabular}{|c|c|}
\hline \multicolumn{2}{|c|}{ Tokopedia } \\
\hline No & Video Likes \\
\hline 1 & 14,100 \\
\hline 2 & 383 \\
\hline 3 & 204 \\
\hline 4 & 25,900 \\
\hline 5 & 27,300 \\
\hline 6 & 12,900 \\
\hline 7 & 16,300 \\
\hline 8 & 18,300 \\
\hline 9 & 14,000 \\
\hline 10 & 4,693 \\
\hline Rata & $\mathbf{1 3 , 4 0 8}$ \\
\hline
\end{tabular}

\begin{tabular}{|c|}
\hline Followers \\
\hline $3,000,000$ \\
\hline Sumber: Pengolahan Data Excel
\end{tabular}


Tabel 2. Analisis Nilai Rata-Rata pada Variabel Video Likes dan Analisis Nilai Variabel Followers Akun TikTok Shopee Indonesia.

\begin{tabular}{|c|c|}
\hline \multicolumn{2}{|c|}{ Shopee } \\
\hline No & Video Likes \\
\hline 1 & 41,300 \\
\hline 2 & 145 \\
\hline 3 & 96 \\
\hline 4 & 97 \\
\hline 5 & 231 \\
\hline 6 & 167 \\
\hline 7 & 256 \\
\hline 8 & 256 \\
\hline 9 & 174 \\
\hline 10 & 220 \\
\hline Rata & $\mathbf{4 , 2 9 4}$ \\
\hline
\end{tabular}

\begin{tabular}{|c|}
\hline Followers \\
\hline $2,500,000$ \\
\hline Sumber: Pengolahan Data Excel
\end{tabular}

Tabel 3. Analisis Nilai Rata-Rata pada Variabel Video Likes dan Analisa Nilai Variabel Followers Akun TikTok Bukalapak.

\begin{tabular}{|c|c|}
\hline \multicolumn{2}{|c|}{ Bukalapak } \\
\hline No & Video Likes \\
\hline 1 & 11 \\
\hline 2 & 12 \\
\hline 3 & 11 \\
\hline 4 & 11 \\
\hline 5 & 30 \\
\hline 6 & 20 \\
\hline 7 & 19 \\
\hline 8 & 15 \\
\hline 9 & 16 \\
\hline 10 & 20 \\
\hline Rata & $\mathbf{1 7}$ \\
\hline
\end{tabular}

\begin{tabular}{|c|}
\hline Followers \\
\hline 379,100 \\
\hline Sumber: Pengolahan Data Excel
\end{tabular}


Tabel 4. Analisis Nilai Rata-Rata pada Variabel Video Likes dan Analisa Nilai Variabel Followers Akun TikTok Lazada Indonesia.

\begin{tabular}{|c|c|}
\hline \multicolumn{2}{|c|}{ Lazada } \\
\hline No & Video Likes \\
\hline 1 & 12 \\
\hline 2 & 18 \\
\hline 3 & 18 \\
\hline 4 & 7 \\
\hline 5 & 21 \\
\hline 6 & 25 \\
\hline 7 & 25 \\
\hline 8 & 39 \\
\hline 9 & 28,000 \\
\hline 10 & 41 \\
\hline Rata & $\mathbf{2 , 8 2 1}$ \\
\hline
\end{tabular}

\begin{tabular}{|c|}
\hline Followers \\
\hline $3,000,000$ \\
\hline Sumber: Pengolahan Data Excel
\end{tabular}

Tabel 5. Analisis Nilai Rata-Rata pada Variabel Video Likes dan Analisa Nilai Variabel Followers Akun TikTok Bliblidotcom.

\begin{tabular}{|c|c|}
\hline \multicolumn{2}{|c|}{ Blibli } \\
\hline No & Video Likes \\
\hline 1 & 9 \\
\hline 2 & 9 \\
\hline 3 & 11 \\
\hline 4 & 17 \\
\hline 5 & 11 \\
\hline 6 & 14 \\
\hline 7 & 12 \\
\hline 8 & 23 \\
\hline 9 & 13 \\
\hline 10 & 19 \\
\hline Rata & $\mathbf{1 4}$ \\
\hline
\end{tabular}

\begin{tabular}{|c|}
\hline Followers \\
\hline 514,700 \\
\hline Sumber: Pengolahan Data Excel
\end{tabular}


Dengan menghitung nilai rata-rata dari variabel Video Likes dan menemukan nilai variabel Follower, maka akan disusun seperti tabel berikut:

Tabel 6. Nilai Variabel pada lima Akun TikTok E-commerce yang banyak dikunjungi di Indonesia

\begin{tabular}{|l|c|c|c|c|c|}
\hline Variabel & Tokopedia & $\begin{array}{c}\text { Shopee } \\
\text { Indonesia }\end{array}$ & Bukalapak & $\begin{array}{c}\text { Lazada } \\
\text { Indonesia }\end{array}$ & Blibli \\
\hline Video likes & 13,408 & 4,294 & 17 & 2,821 & 14 \\
\hline Followers & $3,000,000$ & $2,500,000$ & 379,100 & $3,000,000$ & 514,700 \\
\hline \multicolumn{6}{|c|}{ Sumber: Pengolahan Data Excel }
\end{tabular}

Untuk mengukur kredibilitas pada setiap akun TikTok Terdapat 17 rasion yang relevan. Pada penelitian ini berfokuskan untuk mengkalkulasi Video Likes to Followers Ratio. Penghitung kredibilitas pada setiap E-commerce memiliki rumus: Variabel 1 dibagi Variabel 2, sehingga hasil rasio ditemukan.

Tabel 7. Hasil Perhitungan Rasio Akun TikTok

\begin{tabular}{|c|c|c|c|c|c|c|}
\hline No & Ratio & Tokopedia & Shopee & Bukalapak & Lazada & Blibli \\
\hline & $\begin{array}{c}\text { Video } \\
\text { Likes to } \\
\text { Followers } \\
\text { Ratio }\end{array}$ & 0.00446933 & 0.00171768 & 0.00004352 & 0.00094020 & 0.00002681 \\
\hline
\end{tabular}

Video Likes to Follower Ratio memiliki karakteristik yang tinggi, jadi semakin tinggi nilai yang dihasilkan maka semakin baik kredibilitas dari performa akun tersebut. Pemberian peringkat disetiap E-commerce, penulis memberi angka 5 pada akun E-commerce mendapatkan nilai tertinggi, dan angka 1 untuk E-commerce yang mendapatkan nilai terendah. Berikut tabel urutan peringkat pada masing-masing E-commerce banyak dikunjungi di Indonesia:

Tabel 8. Nilai Rasio 5 E-Commerce yang Banyak Dikunjungi di Indonesia

\begin{tabular}{|c|c|c|c|c|c|}
\hline \multirow{2}{*}{ Ratio } & \multicolumn{5}{|c|}{ Nilai } \\
\cline { 2 - 6 } & Tokopedia & Shopee & Bukalapak & Lazada & Blibli \\
\hline $\begin{array}{c}\text { Video } \\
\text { Likes to } \\
\text { Followers }\end{array}$ & 5 & 4 & 2 & 3 & 1 \\
\hline
\end{tabular}

Dari Tabel Nilai Rasio Akun TikTok 5 E-Commerce yang Banyak Dikunjungi di Indonesia, dapat disimpulkan bahwa Tokopedia mendapat nilai tertinggi (0.00446933) dengan pemberian peringkat 5 pada Video Likes to Followers Ratio. Dan akun TikTok Blibli 
mendapatkan nilai terendah $(0.00002681)$ dengan pemberian peringkat 1 . Jadi, pada penelitian ini akun TikTok Tokopedia memiliki kredibilitas performa yang lebih baik daripada akun E-commerce lainnya.

\section{KESIMPULAN}

Penelitian ini bertujuan untuk mengetahui performa dari 5 akun TikTok e-commerce yang banyak dikunjungi di Indonesia menggunakan analisis Video Likes to Followers Ratio. Lima e-commerce tersebut diantaranya: Tokopedia, Shopee Indonesia, Bukalapak, Lazada Indonesia, dan Blibli. Berdasarkan kelima e-commerce tersebut penulis menarik kesimpulan bahwa:

1. Peringkat pertama diraih oleh e-commerce Tokopedia dengan nilai tertinggi yaitu (0.00446933).

2. Peringkat kedua diraih oleh e-commerce Shopee dengan nilai yaitu (0.00171768).

3. Peringkat ketiga diraih oleh e-commerce Lazada dengan nilai yaitu (0.00094020).

4. Peringkat keempat diraih oleh e-commerce Bukalapak dengan nilai yaitu (0.00004352).

5. Peringkat kelima diraih oleh e-commerce Blibli dengan nilai terendah yaitu (0.00002681). 


\section{DAFTAR PUSTAKA}

Batoebara, Maria Ulfa. 2020. "APLIKASI TIK-TOK SERU-SERUAN ATAU KEBODOHAN." Jurnal Network Media 3 (2): 59-65. https://doi.org/10.46576/jnm.v3i2.849.

Catriana, Elsa. 2021. "5 E-commerce yang Paling Banyak Dikunjungi di Indonesia." Kompas Cyber Media. 2021. https://money.kompas.com/read/2021/02/24/072440626/5-e-commerce-yangpaling-banyak-dikunjungi-di-indonesia.

Dewa, Chriswardana Bayu, dan Lina Ayu Safitri. 2021. "Pemanfaatan Media Sosial Tiktok Sebagai Media Promosi Industri Kuliner Di Yogyakarta Pada Masa Pandemi Covid-19." Khasanah Ilmu : Jurnal Pariwisata Dan Budaya 12 (1): 6571. https://repository.bsi.ac.id/index.php/unduh/item/318017/.

Handy Dwi Wijaya, Mukhammad. 2020. "KONSUMSI MEDIA SOSIALBAGI KALANGAN PELAJAR(STUDI PADA HYPERREALITAS TIK TOK)." AlMada: Jurnal Agama Sosisal dan Budaya 3 (2): 170-91. https://core.ac.uk/reader/327250130.

Permana, I Putu Hendika, dan Ni Putu Suci Meinarni. 2021. "Ratio Analysis on Tiktok (Social Media) for Qualitative Research Using Explorative Methods." Jurnal Ekonomi dan Bisnis Jagaditha 8 (1): 30-38. https://doi.org/10.22225/jj.8.1.2944.30-38.

Rankuti, Freddy. 2015. Riset Pemasaran. Jakarta: Gramedia Pustaka Utama.

Setyowati, Agnes. 2021. "Tiktok, Representasi Keseharian Masyarakat Kita hingga Aksi Sosial." Kompas Cyber Media. 2021. https://www.kompas.com/tren/read/2021/08/01/175240065/tiktok-representasikeseharian-masyarakat-kita-hingga-aksi-sosial.

Suryani, Ita, Akhmad Zulfikri, dan Wulan Muhariani. 2021. "Aplikasi Tik Tok Sebagai Media Kampanye Untuk Pencegahan Penyebaran Covid-19.” Jurnal $\begin{array}{lllll}\text { Ilmu } & \text { Komunikasi } & 8 & \text { (1): }\end{array}$ https://ejournal.bsi.ac.id/ejurnal/index.php/jika/article/view/10542.

Wibowo, Tony, dan Yudi. 2021. "Studi Penetrasi Aplikasi Media Sosial Tik-Tok Sebagai Media Pemasaran Digital: Studi Kasus Kota Batam." Conference on Business, Social Sciences and Technology 1 (1): 662-69. https://journal.uib.ac.id/index.php/conescintech/article/view/5929/1864.

Winarso, Bambang. 2021. “Apa Itu TikTok dan Apa Saja Fitur-fiturnya?” Trikinet. 2021. https://trikinet.com/post/apa-itu-tik-tok/.

Yusuf, Muri. 2017. Metode Penelitian (Kuantitatif, Kualitatif, \& Penelitian Gabungan). Jakarta: Kencana. 